\section{Dr John Kenneth Binns}

\section{Formerly Consultant} Psychiatrist and Physician

Superintendent, Leverndale Hospital, Glasgow

Kenneth was born on 25 June 1928 in Sowerby Bridge, West Yorkshire, the fourth and last child of Ida and John Binns, a pharmacist. After his father's early death, Kenneth joined his two elder brothers at Risworth Boarding School in Yorkshire.

He studied medicine at Edinburgh University graduating MBChB in July 1951 following which he was awarded a Fulbright Scholarship and worked as a rotating intern at Hamot Hospital in Pennsylvania, USA. Fulbright Scholars are selected for their academic merit and leadership potential both of which Kenneth had in abundance.

On his return to the UK he was commissioned in the Royal Army medical Corps (RAMC) to carry out his 2 years national service. In the RAMC he was attached to the 11th Hussars in Malaya as the Regimental Medical Officer (1952-1954)

Kenneth remembered that Sir David Henderson, renowned psychiatrist at the Royal Edinburgh Hospital, had been the most charismatic of his teachers as an undergraduate and so he decided to follow him into psychiatry only to find Sir David had retired the day before he commenced work in 1954. Undaunted Kenneth continued his training at the Royal Edinburgh Hospital, apart from a short spell in Sheffield for some experience in general medicine, under the famous physician Dr A. W. D. Leisman.

Kenneth was appointed as a consultant psychiatrist in Leverndale Hospital in 1964 where he joined an active group of consultants who enabled Kenneth to continue his teaching and research interest.

Throughout his career he taught medical students, junior psychiatric trainees, psychiatric nurses and occupational therapists. He regarded teaching, and passing on his knowledge and skills, as a task to be relished. This resulted in him being a regular invitee to the Glasgow medical graduates' final-year dinners, which continue to be legendary. Indeed, it was through teaching that

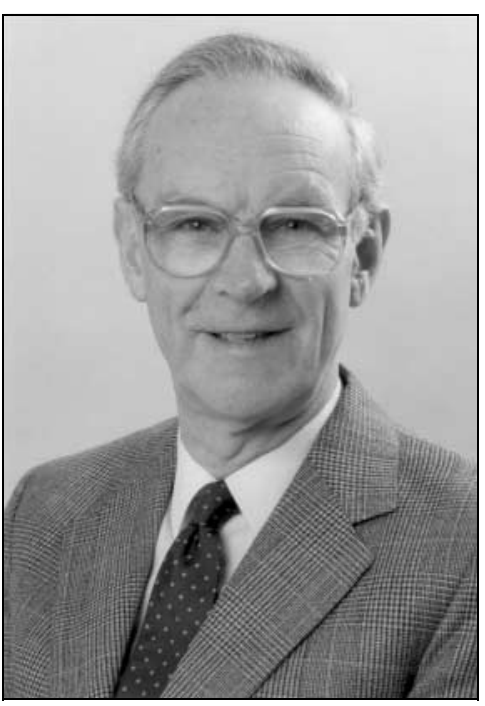

appointment was officially sanctioned in December 1969 and he held the post for 23 years until his retirement in April 1992.

As Physician Superintendent he led the hospital community in all aspects overseeing the up-grading of older Victorian buildings and their replacement with modern admission units and more suitable longer-stay accommodation.

Kenneth always strove to improve care for patients and so, during his time in charge, he recruited young consultants to lead developments in liaison psychiatry, community psychiatry and day care, psychogeriatrics, as it was then called, and rehabilitation psychiatry. The latter was especially successful leading to a large reduction in in-patients and the development of group homes in the community.

He paid attention to the quality of care

he met his beloved wife Sylvia, an occupational therapist by training, who supported Kenneth during some 48 years of happy marriage.

Kenneth had a keen academic mind: he passed the DPM in 1958 and gained his MRCP (Edinburgh) in 1960 to be elected FRCP in 1970 and FRCPsych in 1971. He was involved in a variety of research projects with colleagues such as George Ashcroft, Robin Priest and Donald Eccleston. Kenneth and his consultant colleagues at Leverndale Hospital undertook an extensive review of patients remanded to the Hospital from the courts which was an important addition to Scotland's forensic literature.

He was a founding member of the Royal College of Psychiatrists, and maintained a keen interest in college matters serving on the Scottish Division's executive committee, also as convener of the approvals panel for North West England and treasurer of the Scottish Division's Retired Psychiatrists Group. In this latter role he brought all his years of prudent management skills to bear ensuring the colleagues received 'value for money' at their regular meetings with excellent lunches!

In April 1969, following the sudden and unexpected death of Dr Richard Parks, Kenneth took over as Physician Superintendent at Leverndale Hospital. Kenneth was the unanimous choice of his colleagues despite being one of the most recently appointed consultants: they recognised in him his talents for management and administration. The and to the social environment. He led by example attending all social events in the hospital from the annual Burns supper to every Christmas ward party. It was his warmth and genuine interest in the individual patients which was rewarded in a separate present on his retirement.

He was an important senior medical manager at both local and National level and played a key role in the work of the Scottish Group who produced the definitive work on patients incapable of managing their own affairs. As a result of this work, he co-authored the book on 'Incapax' published in the late 1980s.

After retirement he found time for his much loved family, Sylvia his wife, son lan, daughter Suzanne, and grandchildren Sophie and James, in addition to several cats and dogs. He loved to travel and, despite not being a native Scot, he was an enthusiastic proponent of Scottish country dancing and curling, both of which kept him very fit until he was struck down by pancreatic cancer. He bore the difficulties and pain of that condition during his last few months with fortitude and good humour.

He was a man of great skill and intellect, a warm and caring human being whose legacy is a vibrant community mental health service across south Glasgow, with Leverndale Hospital still a key part of the care which patients and their families can rely upon.

Kenneth died on 1 March 2009.

Linda J. Watt

doi: 10.1192/pb.bp.109.02697 